\title{
Military Nuclear Weapon
}

National Cancer Institute

\section{Source}

National Cancer Institute. Military Nuclear Weapon. NCI Thesaurus. Code C121304.

A military device designed to release energy in an explosive manner as a result of nuclear fission, nuclear fusion, or a combination of the two processes. 